\title{
Experimental Results on Circular and Linear Movements of Two-link Robot Arm \\ Thu Zar ${ }^{1}$, Theingi², Su Yin Win ${ }^{3}$
}

${ }^{* 1}$ Department of Mechanical Engineering, Technological University (Thanlyin), Thanlyin, Yangon, Myanmar

2 Technological University (Thanlyin), Thanlyin, Yangon, Myanmar

${ }^{3}$ Departments of Mechanical Engineering, Technological University (Thanlyin), Thanlyin, Yangon, Myanmar

\begin{abstract}
Robots and manipulators are used to serve machine tools in automatic production system. The robot arm was designed with two degrees of freedom and accomplished accurately simple tasks. This paper represents experimental results on circular movement and straight line movement of two-link manipulator in a vertical movement. The lengths of robot arm links was designed from the desired workspace boundary conditions. Pololu 70:1 gear motors are selected for two joint revolutions of the robot manipulator after analysing the dynamics of two links. To control the robot, it performs inverse kinematic calculations and communicates the proper angles serially to a microcontroller that drives the motors with the capability of modifying position, speed and acceleration. Testing and validation of the robot arm was carried out and results shows that it work properly.
\end{abstract}

Keywords : Robot arm, Manipulator, Motor, Workspace, Kinematic

\section{INTRODUCTION}

The term robotics is practically defined as the study, design and use of robot systems for manufacturing. Robots are generally used to perform unsafe, hazardous, highly repetitive, and unpleasant tasks. They have many different functions such as material handling, assembly, arc welding, resistance welding, and machine tool load and unload functions, painting, spraying, etc. [1].

A two revolute joint robot configuration with two degrees of freedom is generally well-suited for small parts insertion and assembly, like electronic components insertion. Although the final goal is to design and manufacture real robotics, it is very useful to perform simulations prior to investigations with real robots [2].
The development in serial manipulator is advantageous for the researchers for its better control, singular configuration, improving workspace and optimization of the robot arm parameter. The important aspect of dynamic studies of the manipulator is to nature of robot arm behaviour and magnitude of torque, singularity avoidance, power requirements and optimization criterion [3].

A large number of control problems for mechanical systems are based on controlling the position or location of a mass using a force or a torque as the input variable. Instead of the pure regulation problem of driving the output location to a specified value, the position of the mass is often required to follow a prescribed trajectory. Levels of complexity may be added by introducing sets of masses with coupled dynamics, to be controlled by sets of force/torque inputs [4]. 
There are many control techniques used to control a robot arm. The most used ones are the PID control, optimal control, adaptive control and robust control. There are many kinds of controllers that can be used to cause a designed robot arm to move along a desired trajectory. The simplest which it used in this paper to control the robot arm is the PID controller [5].

\section{DESIGN OF TWO-LINK ROBOT ARM}

Firstly, the Robotic Arm is designed in 3D model using the ACAD software. It has two links and two motors for 2DOF planar type manipulator. ATMEGA2560 microprocessor based Arduino MEGA is used for control system using Arduino programming. This process works on the principle of interfacing dc motor. The robot arm joints are typically actuated by electrical motors. The dc motors were chosen, since they include encoders which automatically provide feedback to the motors and adjust the position accordingly. The qualifications of dc motors were selected based on the maximum torque required by the structure and possible loads. In the current study, the material used for the robot arm was aluminium.

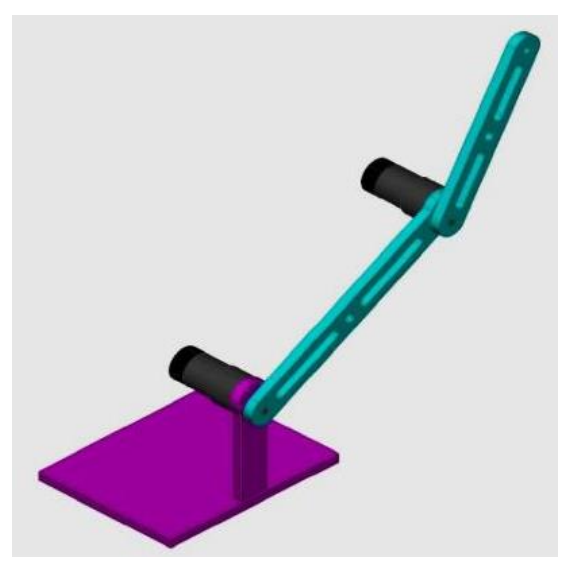

Figure 1. Two-link manipulator CAD model

The two-link robot arm moves in 2D space and the outer boundary of the workspace is considered $40 \mathrm{~cm}$ and the inner boundary is $6 \mathrm{~cm}$. The length of robot manipulator for two links can be calculated using the workspace boundary condition. The robot arm was designed in case of the length of link 1 is longer than the link 2 . The lengths of robot links are calculated by using following equations:

$$
\begin{gathered}
\mathrm{L}_{1}+\mathrm{L}_{2}=40 \\
\mathrm{~L}_{1}-\mathrm{L}_{2}=6
\end{gathered}
$$

Where $\mathrm{L}_{1}>\mathrm{L}_{2}$

Therefore, by using equation (1) and equation (2), the values of $\mathrm{L}_{1}$ and $\mathrm{L}_{2}$ are determined $23 \mathrm{~cm}$ and $17 \mathrm{~cm}$. Figure 2 shows the desired workspace of the two-link manipulator. The specifications of two-link robot arm are shown in Table 1.

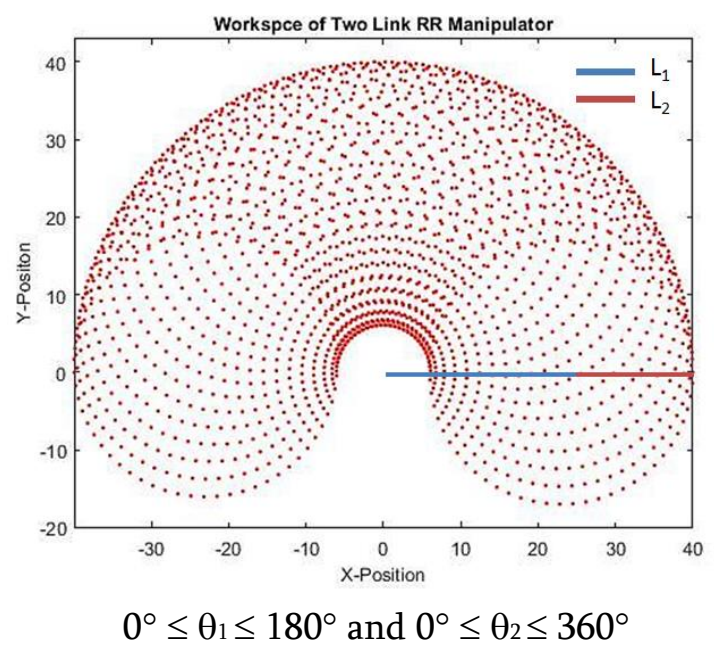

Figure 2. Desired workspace of two-link manipulator TABLE I

MANIPULATORS SPECIFICATIONS

\begin{tabular}{|l|c|c|}
\hline Definition & Value & Units \\
\hline Material & Aluminium & - \\
\hline Density & 0.0027 & $\mathrm{~kg} / \mathrm{cm}^{3}$ \\
\hline Link 1 & $23 \times 3 \times 1$ & $\mathrm{~cm}$ \\
\hline Link 2 & $17 \times 3 \times 1$ & $\mathrm{~cm}$ \\
\hline $\begin{array}{l}\text { Mass of link 1, } \\
\mathrm{m}_{1}\end{array}$ & 0.186 & $\mathrm{~kg}$ \\
\hline $\begin{array}{l}\text { Mass of link 2, } \\
\mathrm{m}_{2}\end{array}$ & 0.138 & $\mathrm{~kg}$ \\
\hline Inertia of link 1, & $8.2 \times 10^{-4}$ & $\mathrm{~kg}-\mathrm{m}^{2}$ \\
\hline
\end{tabular}




\begin{tabular}{|l|l|l|}
\hline $\mathrm{I}_{1}$ & & \\
\hline $\begin{array}{l}\text { Inertia of link 2, } \\
\mathrm{I}_{2}\end{array}$ & $3.324 \times 10^{-4}$ & $\mathrm{~kg}-\mathrm{m}^{2}$ \\
\hline
\end{tabular}

\section{III.DYNAMIC ANALYSIS OF ROBOT ARM}

\section{A. Kinematic Model}

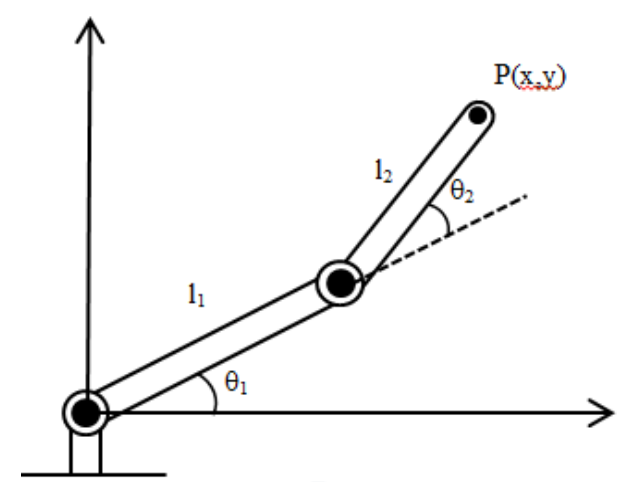

Figure 3. Two-link planar manipulator

Figure 3 shows a schematic representation of two link planar manipulator with link lengths and link angles.

From forward kinematics we have the following relations connecting end effector positions with joint angles and link lengths.

$$
\begin{aligned}
& \mathrm{P}_{\mathrm{x}}=1_{1} \cos \theta_{1}+1_{2} \cos \left(\theta_{1}+\theta_{2}\right) \\
& \mathrm{P}_{\mathrm{y}}=1_{1} \sin \theta_{1}+1_{2} \sin \left(\theta_{1}+\theta_{2}\right)
\end{aligned}
$$

\section{B. Inverse Problem}

The conversion of the position and orientation of a manipulator end effector from Cartesian space to joint space is called as inverse kinematics problem. The inverse kinematics of planar robots is generally easier to find analytically. The short terms of trigonometry are defined by $C_{2}=\cos \theta_{2}$ and $S_{2}=\sin \theta_{2}$. For the joint variable $\theta_{2}$ :

By equation (3) and equation (4), the position of the tip point of the manipulator is at:

$$
\mathrm{P}_{\mathrm{x}}{ }^{2}+\mathrm{P}_{\mathrm{y}}{ }^{2}=\mathrm{l}_{1}^{2}+\mathrm{l}_{2}^{2}+2 \mathrm{l}_{1} \mathrm{l}_{2} \mathrm{C}_{2}
$$

$$
\begin{gathered}
\mathrm{C}_{2}=\frac{\mathrm{P}_{\mathrm{x}}{ }^{2}+\mathrm{P}_{\mathrm{y}}{ }^{2}-\mathrm{l}_{1}^{2}-\mathrm{l}_{2}^{2}}{2 \mathrm{l}_{1} \mathrm{l}_{2}} \\
\theta_{2}=\cos ^{-1} \frac{\mathrm{P}_{\mathrm{x}}{ }^{2}+\mathrm{P}_{\mathrm{y}}{ }^{2}-\mathrm{l}_{1}^{2}-\mathrm{l}_{2}^{2}}{2 \mathrm{l}_{1} \mathrm{l}_{2}}
\end{gathered}
$$

However to avoid using arcsine and arcos because of inaccuracy, it employ the half angle formula.

$$
\tan ^{2} \frac{\theta}{2}=\frac{1-\cos \theta}{1+\cos \theta}
$$

Finally:

$$
\theta_{2}= \pm 2 \operatorname{atan} 2 \sqrt{\frac{\left(\mathrm{l}_{1}+\mathrm{l}_{2}\right)^{2}-\left(\mathrm{P}_{\mathrm{x}}{ }^{2}+\mathrm{P}_{\mathrm{y}}{ }^{2}\right)}{\left(\mathrm{P}_{\mathrm{x}}{ }^{2}+\mathrm{P}_{\mathrm{y}}{ }^{2}\right)-\left(\mathrm{l}_{1}-\mathrm{l}_{2}\right)^{2}}}
$$

The sign ( \pm ) indicates the two postures, "elbow" up and "elbow" down of the manipulator.

For the joint variable $\theta_{1}$ :

$$
\theta_{1}=\operatorname{atan} 2 \frac{P_{x}}{P_{y}} \pm a \tan 2 \frac{1_{2} S_{2}}{1_{1}+1_{2} C_{2}}
$$

\section{Dynamic Analysis}

The dynamic behaviour is described in terms of the time rate of change of the robot configuration in relation to the joint torques exerted by the actuators. This relation can be expressed by a set of differential equations, called equation of motion, that govern the dynamic response of the robot linkage to input joint torques.

The Lagrangian is defined as the difference between the kinetic and potential energy of the mechanical system.

$\mathrm{L}=\mathrm{K}-\mathrm{P}$, where $\mathrm{L}$ is Lagrangian, $\mathrm{K}$ is kinetic energy of the system, and $P$ is the potential energy of the system. Using Lagrangian method, derive the equation of motion for the 2-DOF robot arm, as shown in Figure 4.

Then: 


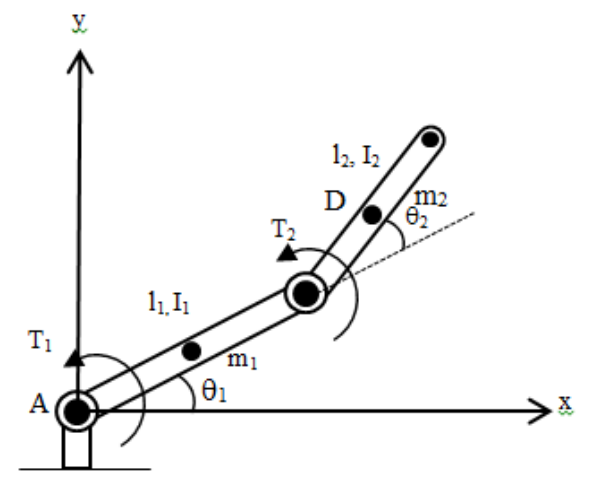

Figure 4. Dynamics analysis of two link manipulator

Frist we calculate the velocity of the center of mass of link 2 by differentiating its position:

$$
\begin{aligned}
& \mathrm{x}_{\mathrm{D}}=\mathrm{l}_{1} \mathrm{C}_{1}+0.5 \mathrm{l}_{2} \mathrm{C}_{12} \\
& \mathrm{y}_{\mathrm{D}}=\mathrm{l}_{1} \mathrm{~S}_{1}+0.5 \mathrm{l}_{2} \mathrm{~S}_{12} \\
& \dot{\mathrm{x}}_{\mathrm{D}}=-\mathrm{l}_{1} \mathrm{~S}_{1} \dot{\theta}_{1}-0.5 \mathrm{l}_{2} \mathrm{~S}_{12}\left(\dot{\theta}_{1}+\dot{\theta}_{2}\right) \\
& \dot{\mathrm{y}}_{\mathrm{D}}=\mathrm{l}_{1} \mathrm{C}_{1} \dot{\theta}_{1}-0.5 \mathrm{l}_{2} \mathrm{C}_{12}\left(\dot{\theta}_{1}+\dot{\theta}_{2}\right)
\end{aligned}
$$

Therefore, the total velocity of the center of mass of link 2 is:

$$
\begin{gathered}
\mathrm{v}_{\mathrm{D}}{ }^{2}=\dot{\mathrm{x}}_{\mathrm{D}}^{2}+\dot{\mathrm{y}}_{\mathrm{D}}^{2} \\
=\dot{\theta}_{1}^{2}\left(\mathrm{l}_{1}^{2}+0.251_{2}^{2}+\mathrm{l}_{1} \mathrm{l}_{2} \mathrm{C}_{2}\right)+\dot{\theta}_{2}^{2}\left(0.251_{2}{ }^{2}\right) \\
+\dot{\theta}_{1} \dot{\theta}_{2}\left(0.51_{2}^{2}+\mathrm{l}_{1} \mathrm{l}_{2} \mathrm{C}_{2}\right)
\end{gathered}
$$

The total kinetic energy of the system is:

$$
\begin{array}{r}
\mathrm{K}=\dot{\theta}_{1}{ }^{2}\left(\frac{1}{6} \mathrm{~m}_{1} \mathrm{l}_{1}^{2}+\frac{1}{6} \mathrm{~m}_{2} \mathrm{l}_{2}{ }^{2}+\frac{1}{2} \mathrm{~m}_{2} \mathrm{l}_{1}{ }^{2}+\frac{1}{2} \mathrm{~m}_{2} \mathrm{l}_{1} \mathrm{l}_{2} \mathrm{C}_{2}\right) \\
+\dot{\theta}_{2}^{2}\left(\frac{1}{6} \mathrm{~m}_{2} \mathrm{l}_{2}^{2}\right)+\dot{\theta}_{1} \dot{\theta}_{2}\left(\frac{1}{3} \mathrm{~m}_{2} \mathrm{l}_{2}{ }^{2}+\frac{1}{2} \mathrm{~m}_{2} \mathrm{l}_{1} \mathrm{l}_{2} \mathrm{C}_{2}\right)
\end{array}
$$

The total potential energy of the system is:

$$
\mathrm{P}=\mathrm{m}_{1} \mathrm{~g} \frac{\mathrm{l}_{1}}{2} \mathrm{~S}_{1}+\mathrm{m}_{2} \mathrm{~g}\left(\mathrm{l}_{1} \mathrm{~S}_{1}+\frac{\mathrm{l}_{2}}{2} \mathrm{~S}_{12}\right)
$$

The Lagrangian for the two-link robot arm will be:

$$
\mathrm{L}=\mathrm{K}-\mathrm{P}
$$

$$
\begin{aligned}
& =\dot{\theta}_{1}^{2}\left(\frac{1}{6} \mathrm{~m}_{1} \mathrm{l}_{1}^{2}+\frac{1}{6} \mathrm{~m}_{2} \mathrm{l}_{2}^{2}+\frac{1}{2} \mathrm{~m}_{2} \mathrm{l}_{1}^{2}+\frac{1}{2} \mathrm{~m}_{2} \mathrm{l}_{1} \mathrm{l}_{2} \mathrm{C}_{2}\right) \\
& +\dot{\theta}_{2}^{2}\left(\frac{1}{6} \mathrm{~m}_{2} \mathrm{l}_{2}^{2}\right)+\dot{\theta}_{1} \dot{\theta}_{2}\left(\frac{1}{3} \mathrm{~m}_{2} \mathrm{l}_{2}^{2}+\frac{1}{2} \mathrm{~m}_{2} \mathrm{l}_{1} \mathrm{l}_{2} \mathrm{C}_{2}\right) \\
& -\mathrm{m}_{1} \mathrm{~g} \frac{1_{1}}{2} \mathrm{~S}_{1}-\mathrm{m}_{2} \mathrm{~g}\left(\mathrm{l}_{1} \mathrm{~S}_{1}+\frac{\mathrm{l}_{2}}{2} \mathrm{~S}_{12}\right)
\end{aligned}
$$

The equation of motion,

$$
\mathrm{T}_{\mathrm{i}}=\frac{\partial}{\partial \mathrm{t}}\left(\frac{\partial \mathrm{L}}{\partial \dot{\theta}_{\mathrm{i}}}\right)-\frac{\partial \mathrm{L}}{\partial \theta_{\mathrm{i}}}
$$

Equation (19) will yield the following two equations of motion

$$
\begin{aligned}
\mathrm{T}_{1}= & \left(\frac{1}{3} \mathrm{~m}_{1} \mathrm{l}_{1}^{2}+\mathrm{m}_{2} \mathrm{l}_{1}^{2}+\frac{1}{3} \mathrm{~m}_{2} \mathrm{l}_{2}^{2}+\mathrm{m}_{2} \mathrm{l}_{1} \mathrm{l}_{2} \mathrm{C}_{2}\right) \ddot{\theta}_{1} \\
& +\left(\frac{1}{3} \mathrm{~m}_{2} \mathrm{l}_{2}^{2}+\frac{1}{2} \mathrm{~m}_{2} \mathrm{l}_{1} \mathrm{l}_{2} \mathrm{C}_{2}\right) \ddot{\theta}_{2}-\left(\mathrm{m}_{2} \mathrm{l}_{1} \mathrm{l}_{2} \mathrm{~S}_{2}\right) \dot{\theta}_{1} \dot{\theta}_{2} \\
& -\left(\frac{1}{2} \mathrm{~m}_{2} \mathrm{l}_{1} \mathrm{l}_{2} \mathrm{~S}_{2}\right) \\
\mathrm{T}_{2}= & \left(\frac{1}{3} \mathrm{~m}_{2} \mathrm{l}_{2}{ }^{2}+\frac{1}{2} \mathrm{~m}_{2} \mathrm{l}_{1} \mathrm{l}_{2} \mathrm{C}_{2}\right) \ddot{\theta}_{1}+\left(\frac{1}{3} \mathrm{~m}_{2} \mathrm{l}_{2}{ }^{2}\right) \ddot{\theta}_{2} \\
& +\left(\frac{1}{2} \mathrm{~m}_{2} \mathrm{l}_{1} \mathrm{l}_{2} \mathrm{~S}_{2}\right) \dot{\theta}_{1}^{2}+\frac{1}{2} \mathrm{~m}_{2} \mathrm{~g} \mathrm{l}_{2} \mathrm{C}_{12}
\end{aligned}
$$

\section{Dynamic Simulation}

The driving torques of the two link manipulator is illustrated in Figure 5 and Figure 6, from the knowledge of the trajectory equation in terms of time. The following simulation results are based on Lagrangian Formulation.
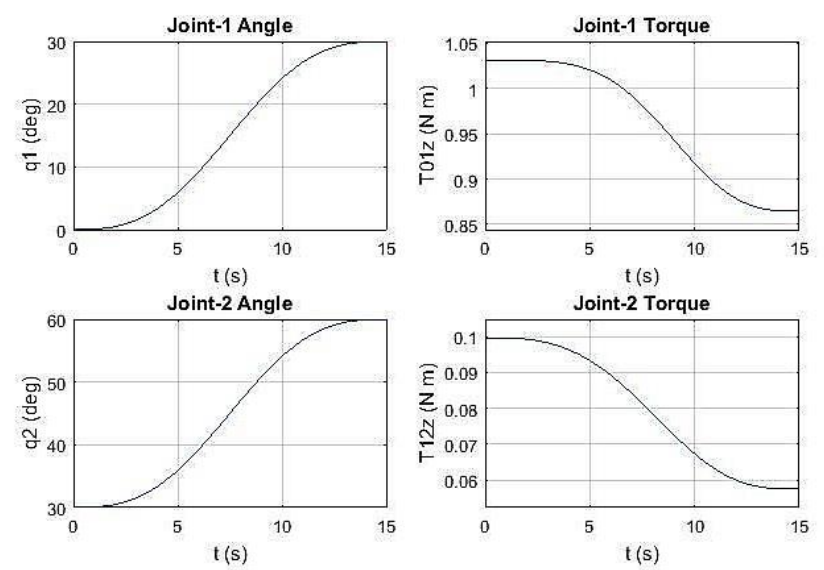

Figure 5. Joint torques $T_{1}$ and $T_{2}$ against time,

$$
\mathrm{q}(1)=0 \sim 30 \text { and } \mathrm{q}(2)=30 \sim 60
$$



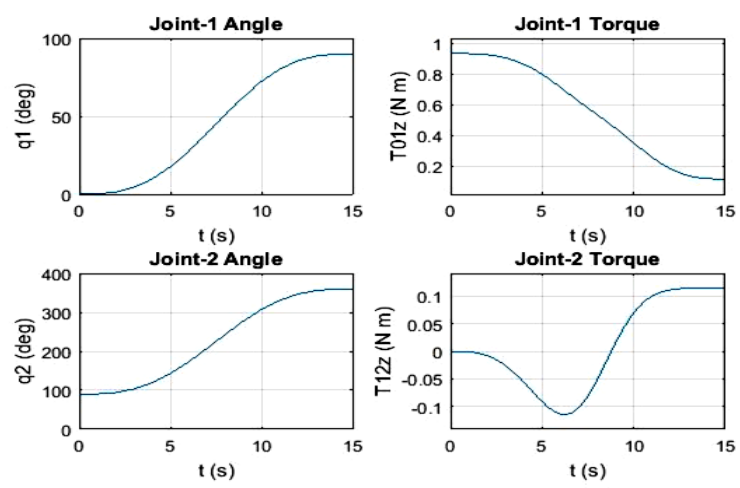

Figure 6. Joint torques $\mathrm{T}_{1}$ and $\mathrm{T}_{2}$ against time, $\mathrm{q}(1)$

$$
=0 \sim 90 \text { and } \quad \mathrm{q}(2)=90 \sim 360
$$

In Figure 5, joint angle $\mathrm{q}(1)$ is set 0 to 30 degree and $\mathrm{q}(2)$ is set 30 to 60 degree. The initial torque for joint 1 is near $1.03 \mathrm{Nm}$ and joint 2 is about $0.1 \mathrm{Nm}$.

In Figure 6, joint angle $\mathrm{q}(1)$ is set 0 to 90 degree and $\mathrm{q}(2)$ is set 90 to 360 degree. The initial torque for joint 1 is near $0.95 \mathrm{Nm}$ and joint 2 is about $0 \mathrm{Nm}$.

According the two simulation results, the maximum torques for joint 1 is about $1.03 \mathrm{Nm}$ and joint 2 is about $0.102 \mathrm{Nm}$. The torque of the pololu 70:1 gear motor is $1.4 \mathrm{Nm}$. Design project for this motor selection is suitable for trajectory tracking control system.

\section{EXPERIMENTAL RESULTS}

For this experiment, two pololu dc motors with encoder are used for both joints revolutions and they have 70:1 gear transmission. Monster motor shield with $12 \mathrm{~V}$ dc $14 \mathrm{~A}$ is used as motor driver.

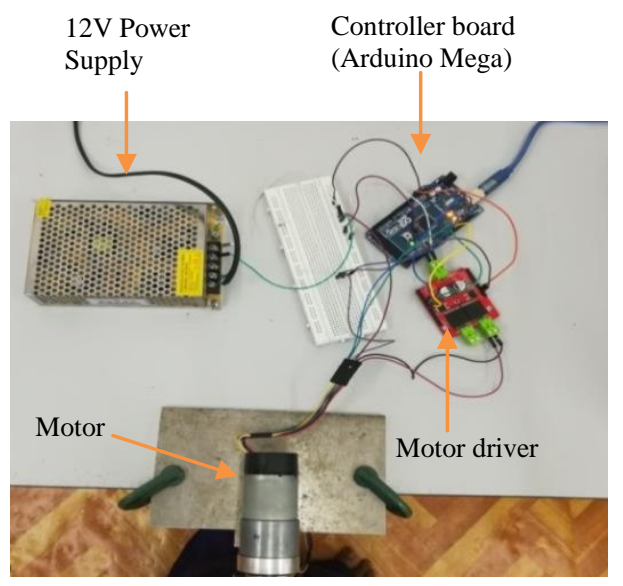

Figure 7. Experimental setup of electrical system
Arduino MEGA is used for the microcontroller of this system and the clock frequency is $16 \mathrm{MHz}$. The microcontroller is connected to computer through USB cable. The encoder resolution is 64 pules per revolution and entire resolution of the motor shaft is 4480 pulses per revolution. $12 \mathrm{~V}$ DC power supply is used for the system. Figures 7 and 8 show the experimental setup of electrical system and two-link manipulator.

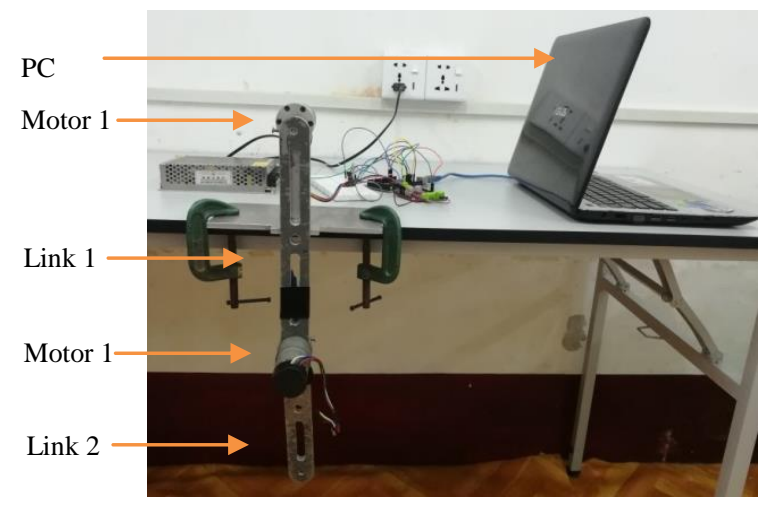

Figure 8. Experimental setup of two-link manipulator

\section{A. Experimental Results on Circular Movement}

In this experimental result, the robot arm is tested for the desired circular movement. Actual and desired $\mathrm{XY}$-position is shown in the following Figure 9. For this experiment results, joint one and joint two results are shown in Figure 10 and joint one and joint two error results are expressed in Figure 11.

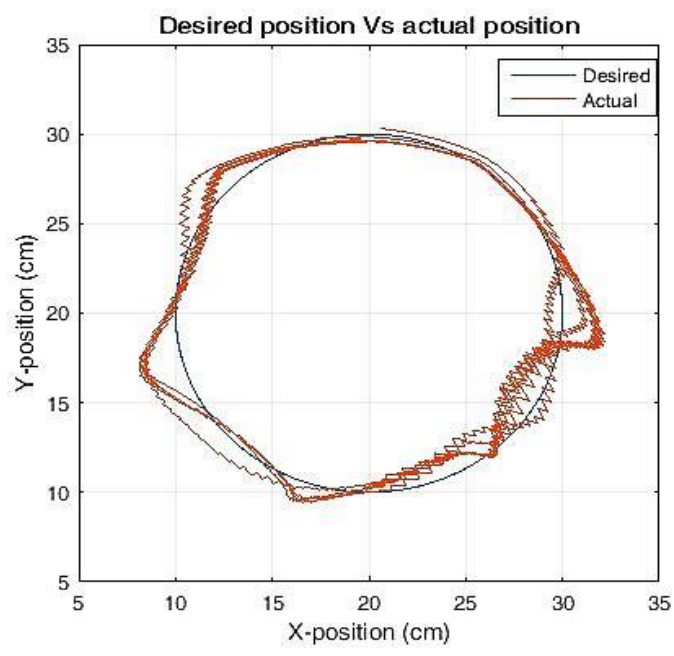

Figure 9. Circular test in XY Position 

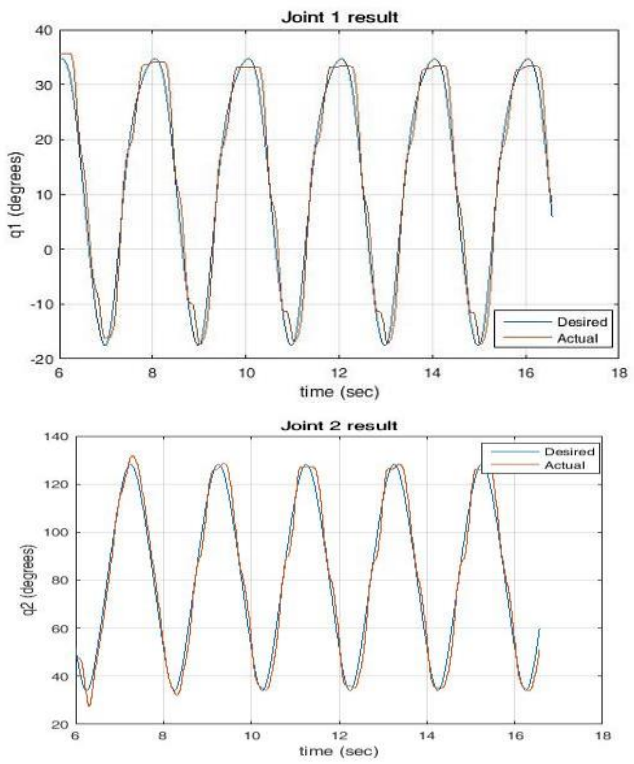

Figure 10. Results of joint one and joint two for circular test
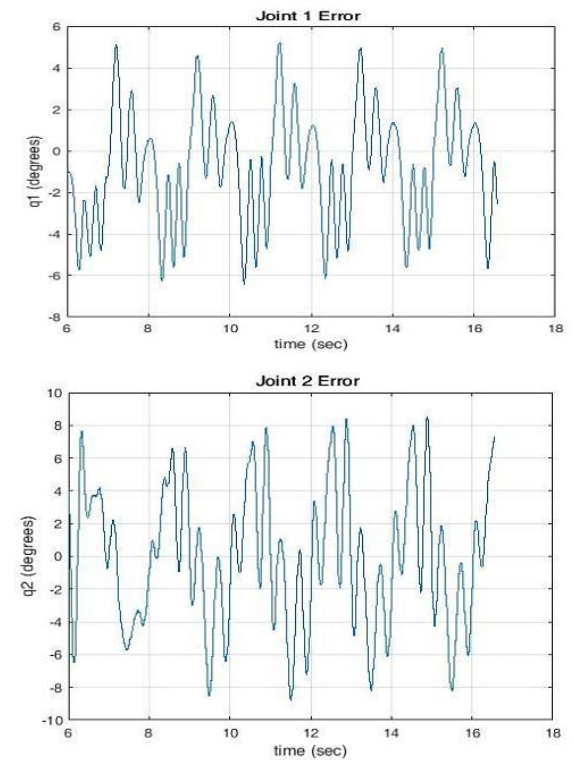

Figure 11. Errors of joint one and joint two for circular test

\section{B. Experimental Results on Linear Movement}

In this experimental result, the robot arm is tested for the desired linear movement. In Linear movement experimental result, actual and desired XY-position is shown in the following Figure 12. For this experiment results, joint one and joint two results are shown in Figure 13 and joint one and joint two error results are expressed in Figure 14.

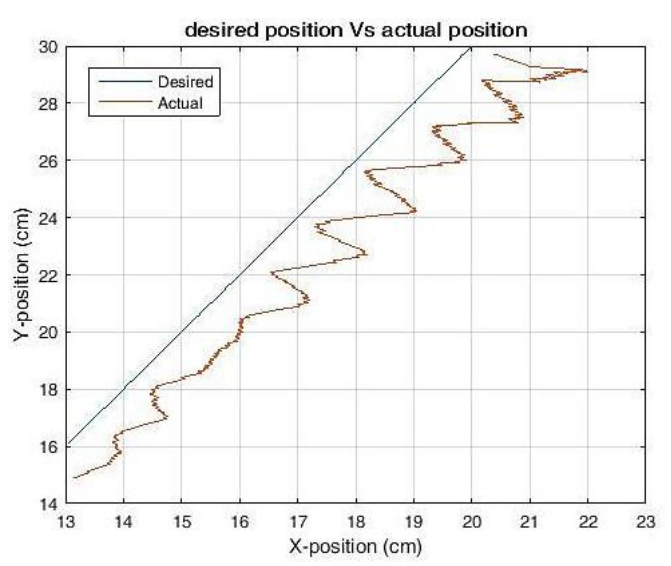

Figure 12. Linear test in XY Position
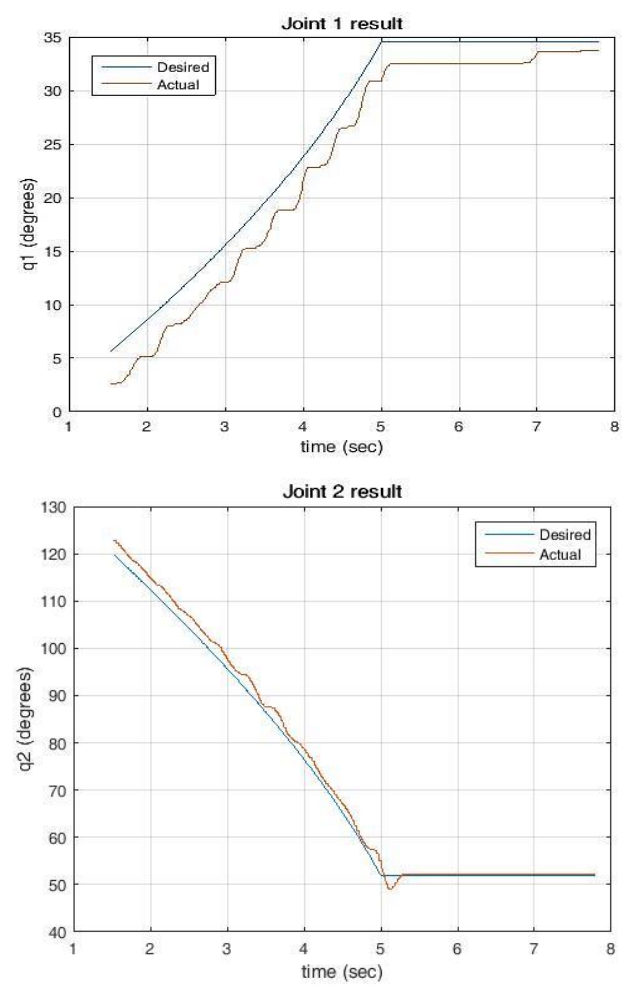

Figure 13. Results of joint one and joint two

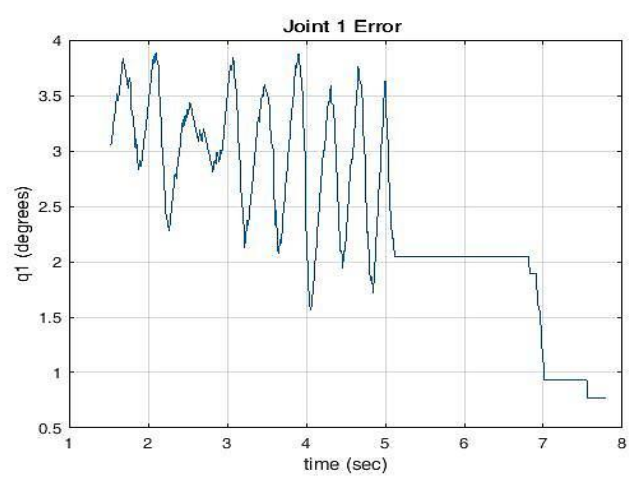




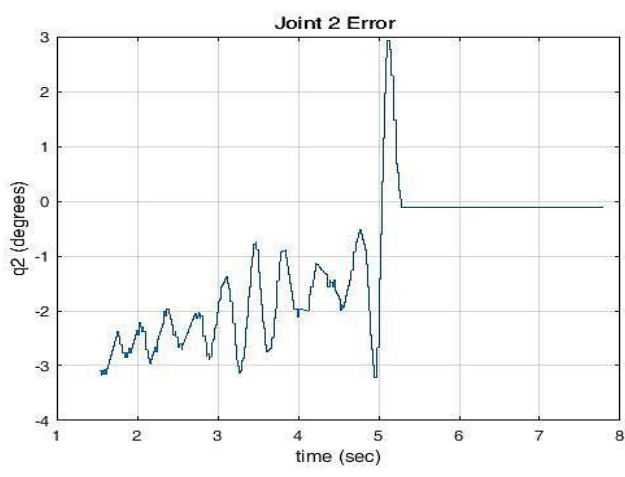

Figure 14. Errors of joint one and joint two for linear test

\section{CONCLUSION}

In this paper, the dynamics analysis of the two-link manipulator by using Lagrangian method and experimental results for desired trajectory are presented. The robot arm has some position errors. A perfect model would contain dynamic effects like joint friction and joint flexibility, and there would be bounds on the maximum input torque for the motors. For position error compensation, controller design should also be recommended for future work.

\section{ACKNOWLEDGEMENT}

The authors wish to thank Department of Mechanical Engineering for permitting to use the facilities to carry out research work.

\section{REFERENCES}

[1] M.H.Ismail, A.N.W.QI, K.L.Voon, M.A.Ismail, N.Mustaffa, "Design and Development of a Mechanism of Robotic Arm for Lifting Parts", $2^{\text {nd }}$ Integrated Design Project Conference (IDPC) 2015

[2] Zlajpah, L. (2008). Simulation in robotics. Mathematics and Computers in Simulation, 79(4), 879-897. doi:10.1016/j.matcom.2008.02.017.
[3] Fernando Reyes, Rafael Kelly, "Experimental evaluation of model based controllers on a direct-drive robot arm", Mechatronics, Vol. 11, P.P. 267-282, 2001

[4] Florin Moldovenau, Vasile Comnac, Dan Floroian, Cristian Boldisor, "Trajectory Tracking Control of a Two-link Robot Manipulator Using Variable Structure System Theory," in CEAI, Vol.7, No.3, PP.56-62, 2005

[5] Aalim M. Mustafa and A AL-SAIF, "Modeling, Simulation and Control of 2-R Robot", Global Journal of Researches in Engineering: $\mathrm{H}$ Robotics and Nano-tech, Volume 14, Issue 1, Version 1.0, 2014

[6] Amin A. Mohammed and M. Sunar, "Kinematics Modeling of a 4-DOF Robotic Arm", Internal Conference on Control, Automation and Robotics 2015, 978-1-46737523-8/15/\$31.00 @2015 IEEE

[7] Mahmoud Gouasmi, Mohammed Ouali, Brahim Fernini, Mohammed Meghatria, "Kinematic Modelling and Simulation of a 2R Robot Using SolidWorks and Verification by MATLAB/Simulink", International Journal of Advanced Robotic Systems, DOI: $10.5772 / 50203$

[8] S K Saha, "Introduction to Robotics"

[9] Amey V.Sutar, Dr. S. S. Ohol, "Kinematic And Dynamic Analysis Of A Robot Arm Used For All Terrain Robot", International Journal of Engineering Research \& Technology (IJERT), Vol. 3 Issue 5, May-2014

[10] Tarun Pratap Singh, Dr. P. Suresh, Dr. Swe Chandan, "Forward and Inverse Kinematic Analysis of Robot Manipulator", International Research Journal of Engineering and Technology (IRJET), Volume: 04 Issue:02, Feb2017

[11] Peter Frankovsky, Darina Hroncova, Ingrid Delyova, Peter Hudak, "Inverse and forward dynamic analysis of two link manipulator", 
www.sciencedirect.com, Procedia Engineering 48 (2012), 158-163

[12] Ruthber Rodriguez Serrezuela, Adrian Fernando Chavarro Chavarro, Miguel Angel Tovar Cardozo, Alejandro Leiva Toquica, Luis Femando Ortiz Martinez, "Kinematic Modelling of a Robotic Arm Manipulator Using MatLab", ARPN Journal of Engineering and Applied Sciences, VOL.12, No. 7, APRIL 2017

[13] Vivek Deshpande, P M George, "Kinematic Modelling and Analysis of 5 DOF Robotic Arm", International Journal of Robotic Research and Developments (IJRRD), Vol. 4, Issue 2, Apr 2014, 17-24 